\section{Annals of Applied Microbiology \& Biotechnology Journal}

\author{
Article Information \\ Received date: Jan 06, 2019 \\ Accepted date: Jan 24, 2019 \\ Published date: Jan 29, 2019 \\ *Corresponding author
}

Kartik S Aiyer, Doctoral Research

Scholar,Department of Biosciences, Sri

Sathya Sai Institute of Higher Learning,

Prasanthi Nilayam, Puttaparthi, Andhra

Pradesh, India, Tel: +917382101074;

Email: aiyerkartiksatyanarayan@sssihl. edu.in

Distributed under Creative Commons CC-BY 4.0

Keywords Biofilm; Electron transfer; Methylene blue; Microbial fuel cells; Wastewater treatment

Article DOI 10.36876/aamb.1011

\section{OPEN ACCESS}

\section{ISSN: 2576-5426}

\section{Assessing Inocula for Microbial Activity and Biofilm Formation for Wastewater Treatment in Microbial Fuel Cells}

\author{
Kartik S Aiyer , Vijayakumar BS \\ Department of Biosciences, Sri Sathya Sai Institute of Higher Learning, India
}

\section{Abstract}

A wide range of inocula are being used for operating microbial fuel cells (MFCs). Inocula containing an active microbial consortium are critical for development of a biofilm on the anode that is ultimately responsible for optimal performance of MFCs. Selection of inoculum harbouring metabolically active microbes is thus essential. In this study, we have used the dye reduction-based electron-transfer activity monitoring assay (DREAM) to assess microbial activity in wastewater samples. Methylene blue was added to different dilutions of domestic wastewater and its subsequent reduction to the colourless state was measured at $660 \mathrm{~nm}$. Microbial electron transfer activity was estimated in terms of DREAM assay coefficient. The wastewater samples were then introduced as anolytes in a microbial fuel cell. Biofilm formation on the anode was estimated using an improvised version of the microtiter dish biofilm assay that allows for rapid and non-invasive detection. The extent of biofilm formation and the subsequent power density produced conformed to the microbial electron transfer activity assessed using the DREAM assay. Cyclic voltammetry and SEM imaging further validated the results obtained. Domestic wastewater was then introduced as the common anolyte for the biofilms developed and substrate reduction in wastewater was evaluated. This work offers novel methods to assess microbial activity in inocula and to assess biofilm formation on anodes in order to suitably select these operating conditions for optimal MFC performance.

\section{Introduction}

New avenues towards sustainable treatment and usage of water are being explored in the wake of water pollution and shortage. Microbial fuel cells (MFCs) offer a platform towards sustainable treatment and reuse of wastewater in the future [1]. MFCs are bioelectrochemical systems that convert chemical energy from organic and inorganic matter into electricity through the use of microbes as catalysts [2]. A microbial fuel cell consists of an anode chamber which houses the microbes in an anaerobic environment and a cathode chamber that maintains aerobic conditions [3]. Oxidation of the substrates by microbes in the anode compartment leads to generation of electrons, which migrate through a circuit towards the cathode [3]. The anode and cathode chambers are separated by a proton exchange membrane, which conducts protons from the anode to the cathode [4]. Microbial fuel cells have assumed an important role in recent years as they offer a practical solution for wastewater treatment and simultaneous generation of power [5].

MFC research is multidisciplinary, integrating knowledge across the fields of electrochemistry, microbiology, materials science, engineering and biotechnology towards practical implementation of wastewater treatment [6]. In this regard, a lot of research has been carried out investigating the operational parameters affecting MFC performance. The choice of the inoculum, the type of culture (pure or mixed), biofilm formation, system design and the properties of materials used as electrodes, separators and proton exchange membranes have an effect on the overall performance of MFCs. MFCs are today being constructed with a variety of different materials, leading to a great diversity of configurations [3]. The type of inocula used in MFCs also vary greatly, ranging from pure or mixed microbial cultures grown in nutrient broth to wastewater from different sources, activated sludge, soil, river sediments and even seawater [7]. As the source of inoculum contains the microbial population that will eventually form a biofilm on the anode, it is crucial to select inocula that harbour metabolically active microbes [8]. It is also crucial to assess biofilm growth on electrodes in a noninvasive manner so as to preserve the anode for future experiments.

In this paper, we present a novel method to assess wastewater samples for their microbial electron transfer activity prior to their introduction as anolytes in a microbial fuel cell. This method is based on the generic dye reduction-based electron-transfer activity monitoring (DREAM) assay previously developed in our lab [9]. We also present an improvised version of the microtiter dish biofilm assay to assess anodic biofilm formation from these samples. The effect of biofilm formation on wastewater treatment is then presented along with electrochemical characterization of the biofilms. The methods presented simplify the procedure for assessing microbial activity in inocula and help in assessing biofilm growth on anodes serving as substratum. 


\section{Materials and Methods}

\section{DREAM Assay for estimating microbial activity}

Wastewater samples that would be used as anolytes in the anode chamber of a microbial fuel cell were tested for their microbial electron transfer activity using DREAM assay [9]. Domestic wastewater was collected from a sewage treatment plant at Prasanthi Nilayam township. Four dilutions of the wastewater (undiluted wastewater $-\mathrm{x}$, $0.75 \mathrm{x}, 0.5 \mathrm{x}$ and $0.25 \mathrm{x}$ ) were subjected to DREAM assay as follows. $0.2 \mu \mathrm{l}$ of methylene blue was added to $2 \mathrm{ml}$ of the wastewater sample taken in a cuvette. Reduction of methylene blue was measured at a wavelength of $660 \mathrm{~nm}$ for a period of 15 minutes at 10 second intervals using a UV-VIS spectrophotometer (SpectraMax M5, Molecular Devices). The control consisted of autoclaved wastewater samples that were subjected to the assay. The extent of reduction was quantified by the DREAM assay coefficient - calculated as the difference between the initial and final absorbance values at $660 \mathrm{~nm}$ for the duration of the assay. DREAM assay coefficient indicates the extent of microbial electron transfer activity present in the sample.

\section{Microbial Fuel Cell}

A five chambered microbial fuel cell was used, consisting of a central cathode chamber $(250 \mathrm{ml})$ and four anode chambers $(150 \mathrm{ml}$ each) made of glass. Carbon cloth was used as the electrode material for cathode $\left(12 \mathrm{~cm}^{2}\right)$ as well as the four anodes $\left(0.5 \mathrm{~cm}^{2}\right.$ each). Cation exchange membrane $\left(7 \mathrm{~cm}^{2}\right.$; Membranes International) was used as the separator. The anolytes in the four anode chambers consisted of domestic wastewater at the above mentioned dilutions $(\mathrm{x}, 0.75 \mathrm{x}, 0.5 \mathrm{x}$, $0.25 \mathrm{x})$. Stirring was ensured for all anolytes. Aerated water was used as the catholyte. Power density curves were obtained using a range of resistors from $15 \mathrm{k} \Omega$ to $330 \mathrm{k} \Omega$. Biofilm formation in each of the anode chambers was monitored and examined using microtiter dish biofilm formation assay and cyclic voltammetry presented below. After biofilm formation, the anolytes in all anode chambers were then replaced with domestic wastewater to determine extent of wastewater treatment with different biofilms.

\section{Microtiter dish biofilm assay}

Biofilms growing on the anodes of the microbial fuel cell were characterized by an improvised microtiter dish biofilm formation assay. Carbon cloth anodes in the microbial fuel cell which formed the substratum for biofilm attachment were rinsed with distilled water and stained with $300 \mu \mathrm{l}$ of $0.1 \%$ crystal violet for 30 minutes. After staining, the anodes were thoroughly washed with distilled water and destained with $200 \mu \mathrm{l}$ of $30 \%$ acetic acid. $100 \mu \mathrm{l}$ of the destaining solution was then transferred to a microtiter dish plate and absorbance was measured at $550 \mathrm{~nm}$. Biofilms growing on the electrodes were classified as strong biofilms, $\mathrm{Abs} \geq 4 \mathrm{x} \mathrm{Abs}$, and moderate biofilms, $2 \times \mathrm{Abs}_{\text {control }}<\mathrm{Abs} \leq 4 \mathrm{x} \mathrm{Abs}_{\text {control }}[10]$.

\section{Electrochemical Measurements}

Cyclic voltammetry (Ivium compactstat) was done to characterize the biofilms developing on each of the anodes. Carbon cloth electrodes from each of the anode chambers of the microbial fuel cell were used as the working electrode, $\mathrm{Ag} / \mathrm{AgCl}$ as the reference electrode and platinum wire as the counter electrode. A scan rate of $20 \mathrm{mV} / \mathrm{s}$ between -800 and $+200 \mathrm{mV}$ was used to obtain cyclic voltammograms to provide details about the electrochemical activity of the biofilm at each of the anodes.

\section{Electron Microscopy}

Biofilms growing on the four anodes were imaged by scanning electron microscopy. The anodes were imaged at $10 \mathrm{kV}$ using a scanning electron microscope (JSM - IT 300). The imaging was conducted at the Central Research Instrumentational Facility, Sri Sathya Sai Institute of Higher Learning (India).

\section{Wastewater Analysis}

Domestic wastewater introduced across the four anode chambers as the common anolyte after biofilm formation was analysed to determine its chemical oxygen demand (COD), biological oxygen demand (BOD), total solids (TS), volatile solids (VS) and sulphates as per standard methods [11]. $\mathrm{pH}$ was measured by a $\mathrm{pH}$ meter (Oakton). Conductivity was measured by a portable pH/ORP/DO conductivity meter (Hach HQ 40d).

\section{Results and Discussion}

\section{DREAM assay determines the microbial electron transfer activity in inocula used as anolytes}

Selection of inoculum which have active exoelectrogens is critical for the operation of microbial fuel cells [8]. In this regard, Song et al.[12] have emphasized the need for an evaluation procedure to assess the microbial activity in inocula for microbial fuel cells. Redox dyes can be used as probes to glean information about microbial activity in the natural environment [13]. Microbial reduction of the redox dye methylene blue is believed to occur directly as a result of the respiratory electron transport chain of microbes [14]. The extent of dye reduction indicates the extent of microbial activity present in the sample.

Reduction of methylene blue by the wastewater samples is depicted in (Figure 1). Among the various wastewater samples used, undiluted wastewater exhibited maximum reduction of methylene blue, thereby generating the highest DREAM assay coefficient of 0.409 . Diluted samples of wastewater $(0.75 \mathrm{x}, 0.5 \mathrm{x}$ and $0.25 \mathrm{x})$ reduced

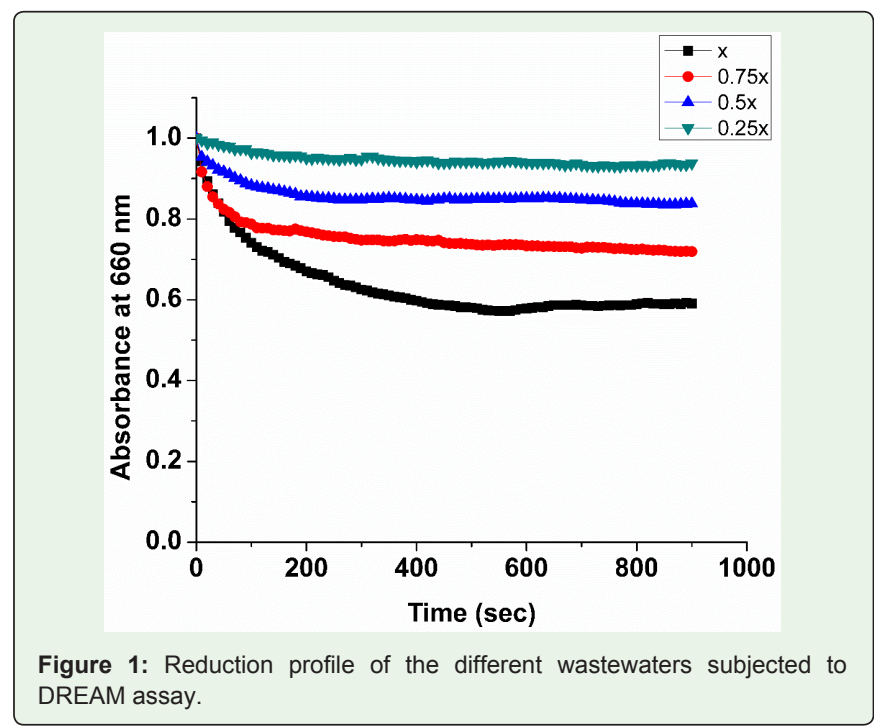


methylene blue to a lesser extent, giving coefficients of $0.280,0.162$ and 0.062 respectively. Autoclaved samples of wastewater did not reduce methylene blue. A higher DREAM assay coefficient indicates greater microbial activity in the sample. Microbes oxidize substrates available to them and use the resulting electrons thereby generated to reduce methylene blue to its colourless state. Reduction of methylene blue is thus dependent not only on the availability of the substrates for oxidation, but also on the metabolic activity of the microbial population [15]. With increasing dilutions, the population of microbes as well as the substrates available to them are reduced, thereby leading to a drop in the DREAM assay coefficient. The DREAM assay can be used as a tool to monitor microbial activity in samples used as inocula in microbial fuel cells.

\section{Power generation in microbial fuel cell}

Power densities obtained were dependent on the organic content present in the wastewater. Undiluted wastewater gave the maximum power density $\left(100.25 \mathrm{~mW} / \mathrm{m}^{2}\right)$, while anode chambers containing $0.75 \mathrm{x}, 0.5 \mathrm{x}$ and $0.25 \mathrm{x}$ dilutions of the wastewater gave power densities of $64.98 \mathrm{~mW} / \mathrm{m}^{2}, 49.20 \mathrm{~mW} / \mathrm{m}^{2}$ and $34.45 \mathrm{~mW} / \mathrm{m}^{2}$ respectively (Figure 2). Maximum power density for all chambers was obtained at a resistance of $100 \mathrm{k} \Omega$. Power density generated in a microbial fuel cell depends on the strength of the wastewater used [16]. In a study where brewery wastewater at different dilutions were used as anolytes in a microbial fuel cell, power generated was observed to be a linear function of the wastewater concentration [16]. The ionic strength of the anolyte also plays an important role in generation of power. Liu et al.[17] have reported that increasing the ionic strength of wastewater from $100 \mathrm{mM}$ to $400 \mathrm{mM}$ lead to an increase in power density from $720 \mathrm{~mW} / \mathrm{m}^{2}$ to $1330 \mathrm{~mW} / \mathrm{m}^{2}$. In this study, dilution of domestic wastewater lead to a drop in the conductivity from $1084 \mu \mathrm{S} / \mathrm{cm}$ to $299 \mu \mathrm{S} / \mathrm{cm}$. Loss of conductivity leads to increased ohmic losses and greater internal resistance[18], which may explain the lesser amount of power produced with diluted wastewater samples.

Apart from ionic strength, $\mathrm{pH}$ also greatly influences the power production in a MFC [19]. Wastewater samples initially introduced in the anodic chambers had a $\mathrm{pH}$ of 7.03. During MFC operation, the $\mathrm{pH}$ in the four anode chambers eventually increased to $8.09,8.04,7.99$ and 7.70 (Figure 3). The cathode, which was common for all anode

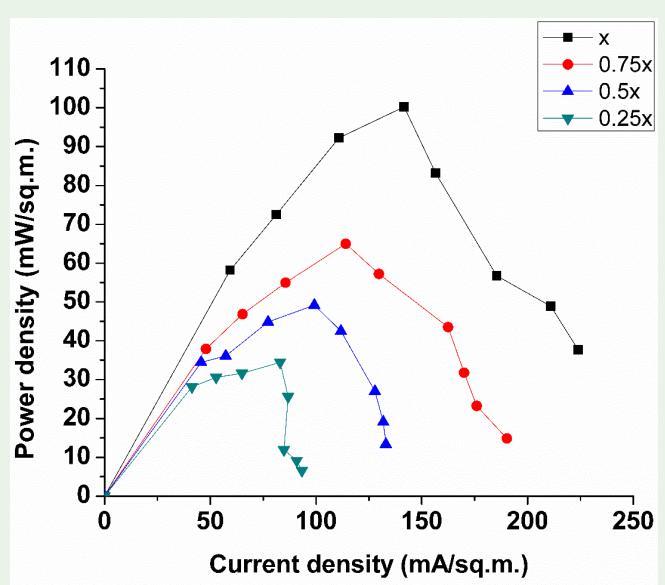

Figure 2: Power density curves for the different dilutions of wastewater used in the microbial fuel cell. chambers, exhibited a drop in $\mathrm{pH}$ from 7 to 2.78 due to accumulation of protons from all anode chambers. The extent of increase in $\mathrm{pH}$ in the anode chambers was dependent on the strength of the wastewater. The anode chamber containing undiluted wastewater demonstrated the greatest increase in anodic $\mathrm{pH}$, while wastewater with greater dilutions demonstrated smaller increments in $\mathrm{pH}$ and subsequently generated smaller power densities. Previous studies regarding anodic $\mathrm{pH}$ conditions have stated that an increased $\mathrm{pH}$ of the anolyte and a decreased $\mathrm{pH}$ of the catholyte is desirable for power generation [20]. Increased anodic $\mathrm{pH}$ leads to a negative anode potential and a positive cathodic potential, making it possible for higher cell voltage to be obtained [21]. Also, mass transfer and ohmic losses are reduced due to rapid consumption of protons at the cathode [22]. A pH range between 6-9 in a MFC is ideal for optimal microbial activity [23]. Continuous operation of a MFC eventually leads to acidification in the anode due to accumulation of protons and their incomplete transfer to the cathode [21]. At the same time, alkalinisation is observed at the cathode [21]. Since the $\mathrm{pH}$ at the anode influences the metabolic activity of microbes and the generation of electrons, it is crucial to maintain a stable $\mathrm{pH}$ value suitable for microbial growth.

Characterization of the biofilms formed at anodes and their effect on wastewater treatment

\section{Microtiter dish biofilm assay for biofilm estimation}

Among the various methods employed for studying biofilm growth and development, the microtiter dish biofilm formation assay developed by Madilyn Fletcher [24] is one of the most common assays used. It is an easy-to-perform and high throughput method that can be used under a wide range of bacterial growth conditions [25]. In this method, the walls of the microtiter well plate are used as substratum for biofilm attachment. Biofilms are stained with crystal violet and destained with acetic acid or ethanol to record absorbance at $550 \mathrm{~nm}$. We have modified this method by eliminating the additional step of growing biofilms on microtiter plate walls and directly treating the substratum (anodes) for biofilm growth with crystal violet to allow direct enumeration of the biofilm formed.

Assessment of bacterial biofilm formation on various surfaces usually involves disruption of the biofilm by vortexing and scraping

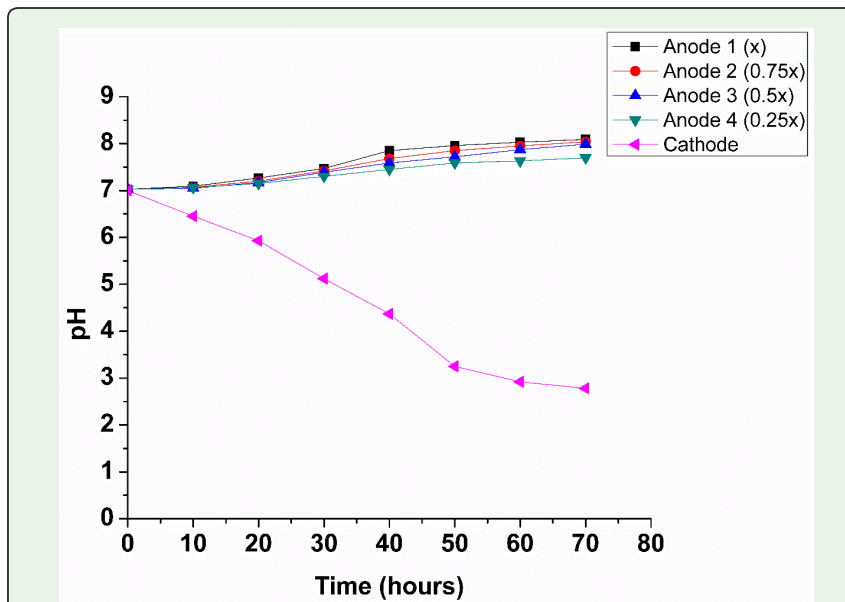

Figure 3: Changes in $\mathrm{pH}$ in the anode and cathode chambers during MFC operation 
[26]. When this method is applied in MFCs, the anode needs to be sacrificed, which places constraints on the lifetime of a microbial fuel cell by not allowing further studies [27]. There is hence a need for a method to study biofilms that does not disrupt the anode in MFCs. The current method used in this study overcomes these problems and preserves the anode for further experiments.

Biofilm growth on anodes of the microbial fuel cell was recorded in terms of absorbance at $550 \mathrm{~nm}$ (Figure 4). The electrode surface acted as substratum for growth of biofilms in the anode chambers. As all other conditions in the anode chamber were similar, the extent of biofilm formation depended upon the strength of wastewater used as anolytes. Strong biofilm growth was observed in the anode chambers where undiluted wastewater and $0.75 \mathrm{x}$ diluted wastewater were used. Increasing the dilutions of the wastewater to $0.5 \mathrm{x}$ and $0.25 \mathrm{x}$ lead to the formation of moderate biofilms. Carbon sources present in the environment strongly influence quorum sensing signals among microbes and their ability to form biofilms [28]. Lack of sufficient carbon sources in the diluted wastewater samples used in this experiment could be a factor for formation of moderately adherent biofilms instead of strongly adherent biofilms.

According to Kumar et al.[29], the first step towards generation of power in a microbial fuel cell is the acclimatization of microbes to the working conditions provided and the formation of a biofilm on the anode surface. Formation of biofilm is vital for electricity generation in MFCs because it significantly improves electron transfer to the anode [30]. Extracellular electron transfer (EET) is thus a means of communicating with the external environment for biofilms[31]. Direct electron transfer (DET) and mediated electron transfer (MET) are the two different mechanisms used by microbes for EET [32]. In DET, microbes develop conductive pili called nanowires on their outer surface that is in contact with the anode. These nanowires conduct electrons to the anode [33]. Outer membrane cytochromes or other related proteins can also be employed by microbes to transfer electrons under DET [32]. MET involves the use of redox molecules as shuttles to transfer electrons to the anode [34]. These mediators are either secreted by the microbes themselves, or can be externally added compounds like methylene blue [35]. Irrespective of the mechanism however, formation of an electroactive biofilm is essential for efficient

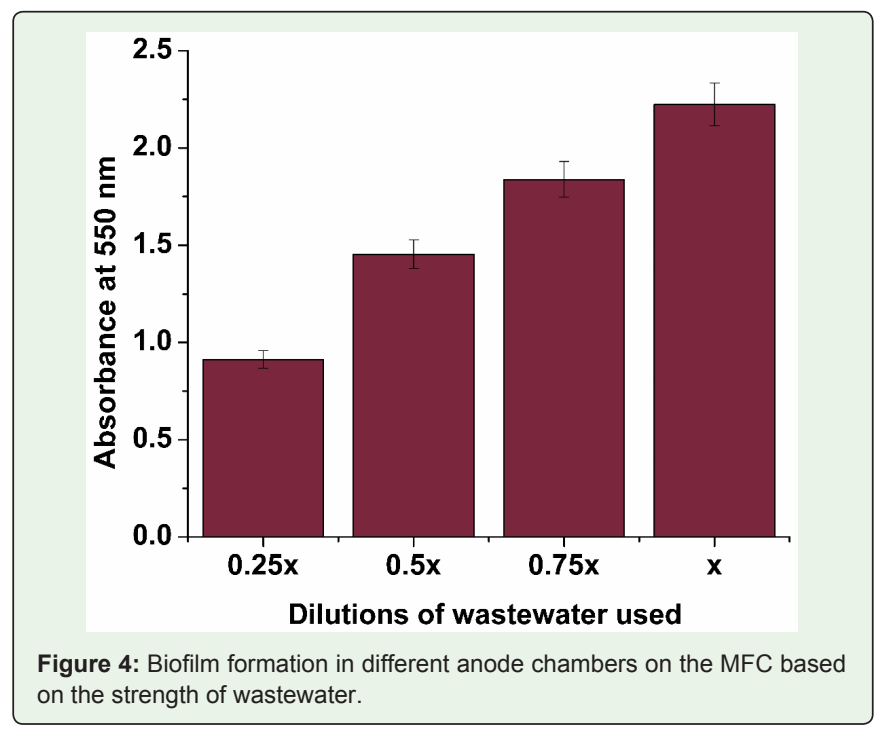

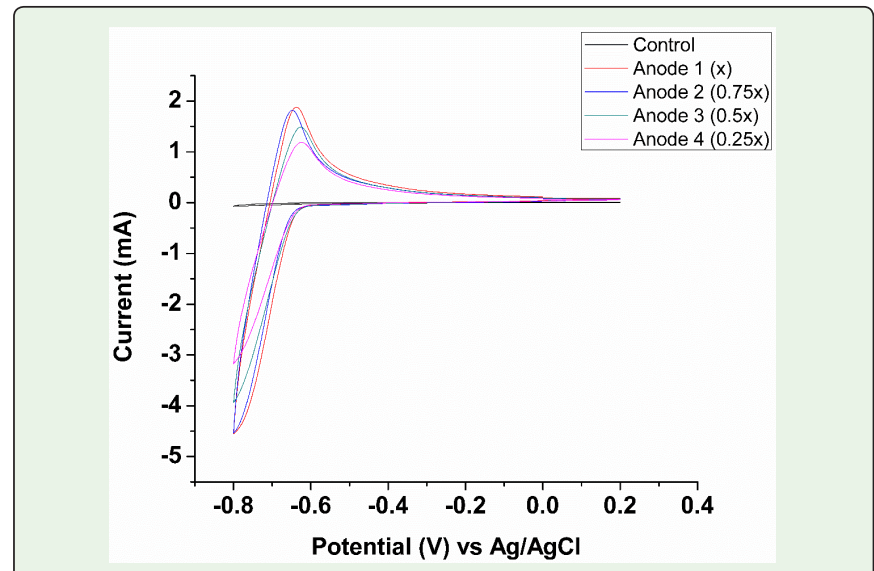

Figure 5: Cyclic voltammograms of the biofilms from each of the anode chambers.

operation of MFCs. It has been reported that thick exoelectrogenic biofilms growing on the surface of the anode generate higher power densities as compared to anodes that do not contain exoelectrogenic biofilms [36]. Microbes that are incompetent at biofilm formation in anodes of MFCs are unable to generate power densities that are significant [37]. It was observed that an enriched consortium of exoelectrogenic bacteria that were able to form biofilms produced $22 \%$ more power than a pure culture of Geobacter sulfurreducens that could not effectively form a biofilm [30]. Mixed culture biofilms developed on anode surfaces from natural environments like sewage and sludge have greater adaptability and resilience [38].

\section{Cyclic Voltammetry and SEM}

Cyclic voltammetry was done to determine the electrochemical activity of biofilms formed at various anodes. Voltammograms obtained for anodes showed peaks of different magnitudes based on the extent of biofilm formation (Figure 5). The control electrode without biofilm growth did not show any redox couple. Largest peak height was observed for the electrode present in the anode chamber containing undiluted wastewater, suggesting enhanced electron transfer to the anode due to formation of electrogenic biofilm [39].

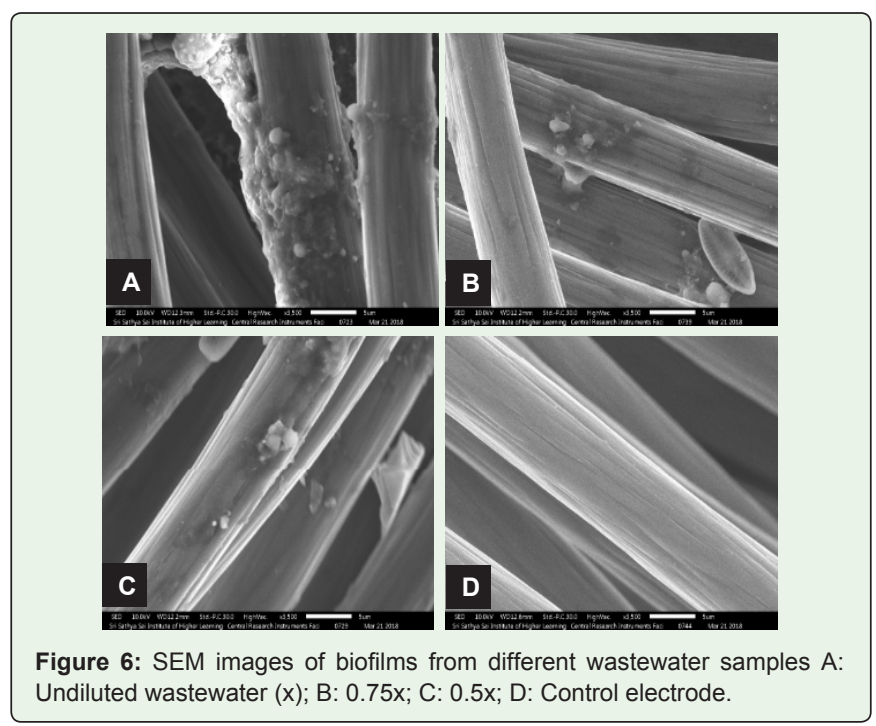


Table 1: Wastewater characteristics in the four anode chambers of the microbial fuel cell before and after treatment.

\begin{tabular}{|c|c|c|c|c|c|}
\hline \multirow{2}{*}{ Domestic Wastewater } & \multirow{2}{*}{ Before Treatment } & \multicolumn{4}{|c|}{ After treatment } \\
\hline & & Anode $1(x)$ & Anode $2(0.75 x)$ & Anode $3(0.5 x)$ & Anode $4(0.25 x)$ \\
\hline $\mathrm{pH}$ & 7.03 & 7.99 & 8.09 & 8.04 & 7.7 \\
\hline Conductivity $(\mu \mathrm{S} / \mathrm{cm})$ & 1084 & 1028 & 779 & 531 & 299 \\
\hline COD (mg/l) & 780.8 & 195.8 & 325.6 & 488.6 & 546.4 \\
\hline $\mathrm{BOD}(\mathrm{mg} / \mathrm{l})$ & 434.5 & 120.8 & 164.7 & 278.6 & 302.6 \\
\hline Sulphates (mg/l) & 4.7 & 3.8 & 4.2 & 4.5 & 4.6 \\
\hline Total Solids (mg/l) & 170.4 & 65.1 & 81.2 & 98.7 & 112.2 \\
\hline Volatile Solids (mg/l) & 132.8 & 57.4 & 65.2 & 78.1 & 88.6 \\
\hline
\end{tabular}

Table 2: Substrate removal (\%) for domestic wastewater in the four anode chambers with different biofilms.

\begin{tabular}{|c|c|c|c|}
\hline \multirow{2}{*}{ Domestic wastewater } & \multicolumn{2}{|c|}{ Substrate removal ratio (\%) } \\
\cline { 2 - 4 } & Anode 1 (x) & Anode 2 (0.75x) & Anode 3 (0.5x) \\
\hline COD & 74.92 & 58.3 & 37.42 \\
\hline BOD & 72.19 & 62.09 & 35.88 \\
\hline Sulphates & 19.15 & 10.64 & 4.26 \\
\hline Total Solids & 61.8 & 52.35 & 42.08 \\
\hline Volatile Solids & 56.78 & 50.9 & 34.15 \\
\hline
\end{tabular}

Lesser extent of biofilm formation on anodes present in diluted wastewaters lead to smaller peak heights. The results likely indicate that the mechanism of electricity generation was by direct transfer of electrons to the electrode by bacteria present on the anode surface [40].

SEM imaging performed revealed extent of biofilm growth on the surface of the anodes. Undiluted wastewater gave a thick mass of biofilm on the anode surface (Figure 6A). With wastewater samples that were diluted, however, bacteria were loosely clumped on the electrode surface (Figure 6B and Figure 6C). The control electrode did not show growth of microbes on the surface (Figure 6D).

\section{Substrate reduction in wastewater}

Table 1 gives the characteristics of domestic wastewater before and after treatment in all the anode chambers of the MFC. The percentage removal ratios for $\mathrm{COD}, \mathrm{BOD}$, total and volatile solids and sulphates in all the anode chambers are tabulated in Table 2. The extent of treatment of domestic wastewater depended on the extent of biofilm formation in all anodes. Increased biofilm formation lead to an increase in the power density produced and also accelerated the wastewater treatment process. Significant removal rates were obtained for COD, BOD, total solids and volatile solids. Removal rate for sulphates however, were not significant. Though sulphate is a potential anaerobic electron acceptor, the small reduction rates of sulphate in the MFC demonstrate that sulphates were not oxidized efficiently. Removal of total solids may be attributed to a process similar to electrochemical salt splitting where a salt dissociates under the influence of external potential gradients [41]. Potential difference generated between the anode and cathode of a MFC due to microbial activity may initiate dissociation of total solids in the anode chamber. Table 3 gives the correlation between the DREAM assay coefficient, biofilm formation, power density and treatment rates. The results clearly indicate that increased biofilm formation on the anode lead to a higher current generation and accelerated organic matter removal in wastewater during the treatment process [42].

Wastewater contains a multitude of organic and inorganic compounds and can be used in MFCs to act as energy sources for microbes to generate electricity [43]. The carbon fraction of the wastewater functions as the electron donor for the metabolism of microbes, simultaneously resulting in substrate degradation and generation of power [44]. According to a study on varying substrate loads used in MFCs, use of wastewater with higher COD concentrations lead to increased biofilm formation and enhanced substrate removal from the wastewater [41]. This improvement in organic matter removal could be explained by two mechanisms, viz. the direct anodic oxidation (DAO) where the contaminants from wastewater are adsorbed onto the anodic surface and are then degraded via electron transfer reactions; and indirect oxidation (IO)

Table 3: Relation between DREAM coefficient, biofilm formation, power density and substrate removal.

\begin{tabular}{|c|c|c|c|}
\hline Inocula & DREAM coefficient & Absorbance at 550nm & Power Density (mw/sq.m.) \\
\hline$x$ & 0.41 & 2.22 & 100.25 \\
\hline $0.75 x$ & 0.28 & 1.84 & 64.98 \\
\hline $0.5 x$ & 0.16 & 1.45 & 49.92 \\
\hline $0.25 x$ & 0.06 & 0.91 & 37.42 \\
\hline
\end{tabular}


involving various oxidants which form electrochemically on the anode surface and help in removal of the pollutants [44]. Initially, oxidation of substrates by the DAO method leads to formation of oxidants, which then accelerate organic matter removal through the IO method [44]. It has been proposed that integrating biological treatment with electrochemical oxidation in a MFC can enhance the substrate removal process [44].

\section{Conclusions}

Looking from a biological perspective, maximizing the efficiency of microbes present in inocula towards oxidation of substrates in wastewater is critical for practical applications. The DREAM assay makes it possible to screen inocula for their exoelectrogenic activity. It is a rapid, cost-effective, cultivation independent and easy-toperform assay and circumvents the problem of using multiple MFCs to test inocula for their microbial activity. The sensitivity of the assay can be enhanced by addition of simple carbon sources that serve as substrates for microbes. The improvised form of microtiter dish biofilm assay presented in this work can be applied to determine the propensity of different electrode materials to support biofilm growth Accordingly, electrode materials for MFCs can be suitably engineered to maximize microbial colonization and aid biofilm growth Domestic, agricultural and industrial wastewaters are generated all over the world in high quantities and are thus potential sources of feed to MFCs. Careful consideration of wastewater characteristics in order to maximise treatment via biological processes is essential.

\section{Acknowledgement}

The authors thank Bhagawan Sri Sathya Sai Baba for his constant guidance and support. The authors also acknowledge the Central Research Instrumentational Facility of the Sri Sathya Sai Institute of Higher Learning for providing research facilities.

\section{Nomenclature}

DREAM: Dye Reduction-based Electron-transfer Activity Monitoring

MFC: Microbial Fuel Cell

COD: Chemical Oxygen Demand

BOD: Biological Oxygen Demand

TS: Total Solids

VS: Volatile Solids

\section{References}

1. Logan BE, Rabaey K. Conversion of wastes into bioelectricity and chemicals by using microbial electrochemical technologies. Science. 2012; 337: 686-690.

2. Rabaey K, Rodríguez J, Blackall LL, Keller J, Gross P, Batstone D, et al Microbial ecology meets electrochemistry: electricity-driven and driving communities. ISME J. 2007; 1: 9-18.

3. Logan BE, Hamelers B, Rozendal R, Schröder U, Keller J, Freguia S, et al Microbial Fuel Cells: Methodology and Technology. Environ Sci Technol. 2006; 40: 5181-5192.

4. Oh SE, Logan BE. Proton exchange membrane and electrode surface areas as factors that affect power generation in microbial fuel cells. Appl Microbiol Biotechnol. 2006; 70: 162-169.
5. Santoro C, Arbizzani C, Erable B, leropoulos I. Microbial fuel cells: From fundamentals to applications. A review. J Power Sources. 2017; 356: 225-244

6. Rinaldi A, Mecheri B, Garavaglia V, Licoccia S, Di Nardo P, Traversa E. Engineering materials and biology to boost performance of microbial fuel cells: a critical review. Energy Environ Sci. 2008; 1: 417-429.

7. Yates MD, Kiely PD, Call DF, Rismani-Yazdi H, Bibby K, Peccia J, et al. Convergent development of anodic bacterial communities in microbial fuel cells. ISME J. 2012; 6: 2002-2013.

8. Schaetzle O, Barrière F, Baronian K. Bacteria and yeasts as catalysts in microbial fuel cells: electron transfer from micro-organisms to electrodes for green electricity. Energy Environ Sci. 2008; 1: 607-620.

9. Vishwanathan AS, Devkota R, Siva Sankara Sai S, Rao G. DREAM Assay for Studying Microbial Electron Transfer. Appl Biochem Biotechnol. 2015; 177: 1767-1775.

10. Stepanović S, Vuković D, Dakić I, Savić B, Švabić-Vlahović M. A modified microtiter-plate test for quantification of staphylococcal biofilm formation. J Microbiol Methods. 2000; 40: 175-179.

11. Association APH, Association AWW. Standard methods for examination of water and wastewater. In Standard methods for examination of water and wastewater. APHA 1998

12. Song TS, Cai HY, Yan ZS, Zhao ZW, Jiang HL. Various voltage productions by microbial fuel cells with sedimentary inocula taken from different sites in one freshwater lake. Bioresour Technol. 2012; 108: 68-75.

13. Tratnyek PG, Reilkoff TE, Lemon AW, Scherer MM, Balko BA, Feik LM, et al. Visualizing Redox Chemistry: Probing Environmental Oxidation?Reduction Reactions with Indicator Dyes. Chem Educator. 2001; 6: 172-179.

14. Hazan R, Que YA, Maura D, Rahme LG. A method for high throughput determination of viable bacteria cell counts in 96-well plates. BMC Microbiol. 2012; 12: 259 .

15. Chen BY. Understanding decolorization characteristics of reactive azo dyes by Pseudomonas luteola: toxicity and kinetics. Process Biochemistry. 2002; 38: $437-446$

16. Feng $Y$, Wang $X$, Logan $B E$, Lee $H$. Brewery wastewater treatment using air-cathode microbial fuel cells. Appl Microbiol Biotechnol. 2008; 78: 873-880.

17. Liu H, Cheng S, Logan BE. Power generation in fed-batch microbial fuel cells as a function of ionic strength, temperature, and reactor configuration. Environ Sci Technol. 2005; 39: 5488-5493.

18. Clauwaert $P$, Aelterman $P$, Pham TH, De Schamphelaire L, Carballa M, Rabaey K, et al. Minimizing losses in bio-electrochemical systems: the road to applications. Appl Microbiol Biotechnol. 2008; 79: 901-913

19. Patil SA, Harnisch F, Koch C, Hübschmann T, Fetzer I, CarmonaMartínez AA, et al. Electroactive mixed culture derived biofilms in microbial bioelectrochemical systems: The role of $\mathrm{pH}$ on biofilm formation, performance and composition. Bioresour Technol. 2011; 102: 9683-9690.

20. Jadhav GS, Ghangrekar MM. Performance of microbial fuel cell subjected to variation in $\mathrm{pH}$, temperature, external load and substrate concentration. Bioresour Technol. 2009; 100: 717-723.

21. Zhuang L, Zhou S, Li Y, Yuan Y. Enhanced performance of air-cathode two-chamber microbial fuel cells with high-pH anode and low-pH cathode. Bioresour Technol. 2010; 101: 3514-3519.

22. Erable B, Etcheverry L, Bergel A. Increased power from a two-chamber microbial fuel cell with a low-pH air-cathode compartment. Electrochemistry Communications. 2009; 11: 619-622.

23. Oliveira VB, Simões M, Melo LF, Pinto AMFR. Overview on the developments of microbial fuel cells. Biochemical Engineering Journal. 2013; 73: 53-64

24. Azeredo J, Azevedo NF, Briandet R, Cerca N, Coenye T, Costa AR, et al. Critical review on biofilm methods. Crit Rev Microbiol. 2017; 43: 313-351. 
25. O'Toole GA. Microtiter Dish Biofilm Formation Assay. J Vis Exp. 2011; 2437.

26. Pettit RK, Weber CA, Kean MJ, Hoffmann H, Pettit GR, Tan R, et al. Microplate Alamar Blue Assay for Staphylococcus epidermidis Biofilm Susceptibility Testing. Antimicrob Agents Chemother. 2005; 49: 2612-2617.

27. Donovan C, Dewan A, Heo D, Beyenal H. Batteryless, Wireless Sensor Powered by a sediment Microbial Fuel Cell. Environ Sci Technol. 2008; 42 8591-8596.

28. Andersson S, Kuttuva Rajarao G, Land CJ, Dalhammar G. Biofilm formation and interactions of bacterial strains found in wastewater treatment systems. FEMS Microbiol Lett. 2008; 283: 83-90.

29. Kumar R, Singh L, Zularisam AW, Hai FI. Microbial fuel cell is emerging as a versatile technology: a review on its possible applications, challenges and strategies to improve the performances. International Journal of Energy Research. 2018; 42: 369-394.

30. Reguera G, Nevin KP, Nicoll JS, Covalla SF, Woodard TL, Lovley DR Biofilm and Nanowire Production Leads to Increased Current in Geobacter sulfurreducens Fuel Cells. Appl Environ Microbiol. 2006; 72: 7345-7348.

31. More TT, Yadav JS, Yan S, Tyagi RD, Surampalli RY. Extracellular polymeric substances of bacteria and their potential environmental applications. J Environ Manage. 2014; 144: 1-25.

32. Patil SA, Hägerhäll $C$, Gorton L. Electron transfer mechanisms between microorganisms and electrodes in bioelectrochemical systems. In Advances in Chemical Bioanalysis. 2012 Cham: Springer International Publishing.

33. Reguera G, McCarthy KD, Mehta T, Nicoll JS, Tuominen MT, Lovley DR. Extracellular electron transfer via microbial nanowires. Nature. 2005; 435 : 1098-1101.

34. Kumar R, Singh L, Zularisam AW. Exoelectrogens: Recent advances in molecular drivers involved in extracellular electron transfer and strategies used to improve it for microbial fuel cell applications. Renewable and Sustainable Energy Reviews. 2016; 56: 1322-1336.

35. Schröder U. Anodic electron transfer mechanisms in microbial fuel cells and their energy efficiency. Phys chem chem phys. 2007; 9: 2619-2629.
36. Logan BE. Exoelectrogenic bacteria that power microbial fuel cells. Nat Rev Microbiol. 2009; 7: 375-381.

37. Kumar R, Singh L, Wahid ZA, Din MFM. Exoelectrogens in microbial fuel cells toward bioelectricity generation: a review. International Journal of Energy Research. 2015; 39: 1048-1067.

38. Liu Y, Harnisch F, Fricke K, Schröder U, Climent V, Feliu JM. The study of electrochemically active microbial biofilms on different carbon-based anode materials in microbial fuel cells. Biosens Bioelectron. 2010; 25: 2167-2171.

39. Islam MA, Karim A, Woon CW, Ethiraj B, Cheng CK, Yousuf A, et al. Augmentation of air cathode microbial fuel cell performance using wild type Klebsiella variicola. RSC Adv. 2017; 7: 4798-4805

40. Egbadon E, Akujobi CO, Nweke CO, Braide, W, Akaluka CK, Adeleye SA. Simultaneous Generation of Bioelectricity and Treatment of Swine Wastewater in a Microbial Fuel Cell. International Letters of Natural Sciences. 2016; 54: 100-107.

41. Mohan SV, Raghavulu SV, Peri D, Sarma PN. Integrated function of microbial fuel cell (MFC) as bio-electrochemical treatment system associated with bioelectricity generation under higher substrate load. Biosens Bioelectron. 2009; 24: 2021-2027.

42. Ishii S, Suzuki S, Norden-Krichmar TM, Wu A, Yamanaka Y, Nealson KH, et al. Identifying the microbial communities and operational conditions for optimized wastewater treatment in microbial fuel cells. Water Res. 2013; 47: 7120-7130

43. Pandey P, Shinde VN, Deopurkar RL, Kale SP, Patil SA, Pant D. Recent advances in the use of different substrates in microbial fuel cells toward wastewater treatment and simultaneous energy recovery. Applied Energy. 2016; 168: 706-723.

44. Mohanakrishna G, Venkata Mohan S, Sarma PN. Bio-electrochemical treatment of distillery wastewater in microbial fuel cell facilitating decolorization and desalination along with power generation. J Hazard Mater. 2010; 177: 487-494. 